La expansión y desarrollo del castellano parecen justificar una interpretación bastante monolítica y carente de matices de lo que fue su implantación en América. La independencia misma de las naciones latinoamericanas se hace, aparentemente sin ningún asomo de conflicto o sentimiento de contradicción, en la lengua de la metrópolis. Introduciendo un poco de perturbación en este panorama, aquí analizaremos el caso particular de Chile donde, tras la independencia, imperó durante más de cien años un curioso ambiente de caos y polémicas ortográficas que no se apaga sino hasta 1927, y aún entonces, sólo por decreto gubernamental. La traducción milita en este campo de polémicas, y en algunos casos se vuelve eje mismo de la controversia.

PALABRAS CLAVE: reforma ortográfica, independencia hispanoamericana, Chile, neografía, Bello, Sarmiento.

\title{
Tradukzión
}

\section{i rrebelión ortográfika}

Gertrudis Payàs

Universidad Católica de Temuco, Chile
The expansion and development of Spanish in the world today would seem to support a rather seamless interpretation of the establishment of this language in America. It is generally assumed that it is in Spanish that these nations fought their independence, apparently without experiencing any conflict about the fact that they were nevertheless adopting the colonial language. In our study we will introduce some disturbance in the picture by analyzing the particular case of Chile, where a curious climate of chaos and controversy prevaled for more than a century over the proper spelling of Spanish until, in 1927, a government decree brought orthograph into compliance with the Spanish acedemic rule. Translation was part of this controversy, sometimes even central to it.

KEYWORDS: spelling reform, Spanish American Independence, Chile, Bello, Sarmiento. 


\section{TRADUKZION I RREBELIÓN ORTOGRÁFIKA ${ }^{\mathrm{I}}$}

El I3 de marzo de i892, con el título «Abiso á 16 los qomerciantes», el funcionario encargado de la inspección de pesas y medidas de la ciudad de Valparaíso, en Chile, informaba a los comerciantes por medio de una inserción en los distintos periódicos de la ciudad de que procedería en esas fechas a realizar las inspecciones de rigor. El anuncio rezaba así:

El Fiel Ejequtor de la 2a. seqzion de esta ziudad aze saber á los qomerziantes qe a qomenzado su bisita de qomprobazion de las pesas y medidas.

Su ofizina está situada en la qalle de Blanqo, núm. I8R y se enqontrará abierta de I a 5 P.M.

Teniendo qonozimiento de qe muchos qomerziantes no dan fiel qumplimiento a la lei de 28 de enero de 1848 ni tampoqo al deqreto de fecha 30 de diziembre de 1870 , espedido por esta Intendenzia de Balparaiso, dando para ello qomo única esqusa (la qual en realidad qareze de todo balor), la ignoranzia de las leyes, bengo en reqordarles el artículo 15 de la lei del 48 (Contreras, I993: 214).

Por muy oficial que sonara el anuncio y que fuera el cargo del funcionario en cuestión -O quizás precisamente por ello-, las reacciones fueron inmediatas. Durante varios días, diversos periódicos recibieron y publicaron protestas y burlas, que fueron respondidas con «enqomiable qomedimiento" por el Fiel Ejequtor, de nombre Carlos Cabezón, identificado como «neógrafo» y partidario de un movimiento que propugnaba una «ortografía rrazional».

En auxilio suyo acudía otro neógrafo: don Carlos Newman, bajo seudónimo, como era frecuente en estas polémicas, citando en su defensa

I En todas las citas de este texto, naturalmente, se respeta la ortografía original. al insigne académico venezolano Andrés Bello (I78I-I865), precursor de la reforma ortográfica del castellano en Hispanoamérica. El conocido periodista Rafael Egaña, en una respuesta publicada también en el periódico, sentenciaba: «aun los que no aceptamos la nueva ortografía, debemos reconocer que sus apóstoles tienen razón ... Si la v y la $b$ tienen un mismo sonido, si el de la $g$ y la $j$ se confunden en ciertos casos, si la $u$ no suena a veces, si la $b$ no suena nunca, no hay argumento alguno capaz de convencer á nadie de que estas letras deben subsistir» (Contreras, 1993: 223).

Resumido de esta forma tenemos el contencioso ortográfico que reinó durante más de cien años, desde I823 hasta I927, en Chile, una de las ex colonias españolas más alejadas del brazo de la Real Academia de la Lengua.

En la historia de la ortografía de la lengua castellana, el caso del castellano adoptado en las colonias merece una atención particular, en virtud de que en Hispanoamérica la discusión ortográfica fue amplia y prolongada, y estuvo teñida de matices ideológicos e incluso directamente políticos. Sin embargo, aun conociéndose las circunstancias, este hecho no parece haber suscitado interés per se, sino como anécdota dentro del ámbito de la filología. Repasando la bibliografía moderna, hay que señalar que, pese a su trasfondo ideológico, en los estudios literarios postcoloniales del ámbito hispano no se ha prestado ninguna atención, que sepamos, a las vicisitudes de la ortografía. De hecho, incluso, cuando se ha discutido la pertinencia de los marcos teóricos del postcolonialismo al caso hispanoamericano, una de las razones aducidas para la dificultad de su aplicación (fuera de los estudios literarios del periodo colonial ${ }^{2}$ ) es el hecho de que las nuevas naciones hayan

\footnotetext{
2 En particular Walter Mignolo (1986 y 1997).
} 
adoptado, aparentemente sin conflicto ni contradicción, el español o castellano como lengua oficial y común ${ }^{3}$. En los estudios de historia intelectual sobre construcción de identidades latinoamericanas (véase, por ejemplo, Granados y Marichal, 2004) se da también por sentado que la base lingüística la constituye un castellano no diferenciado del castellano peninsular. Se asume que las independencias, obra de los criollos, se hicieron en el castellano peninsular (al fin y al cabo, las constituciones respectivas se redactaron en esa lengua).

La historia literaria de las naciones americanas no se ha ocupado tampoco del tema ortográfico, posiblemente porque no se relaciona directamente con el uso literario de la lengua. En las historias literarias americanas se consignan las rupturas respecto al español peninsular sobre todo en aspectos del léxico (incorporación temprana de americanismos en la narrativa de autores como Miguel Ángel Asturias), aspectos estilísticos (experimentación en las vanguardias poéticas: César Vallejo, Oliverio Girondo, Vicente Huidobro), o de poética (diglosia castellano-quechua en José María Arguedas, por ejemplo). Estas rupturas, si bien en algunos casos afectan la ortografía ${ }^{4}$, pertenecen al orden estético, lo que las sitúa en un plano distinto del que aquí nos interesa. Donde sí se encuentran expuestas es, desde luego, en los estudios dedicados a las figuras de Andrés Bello y Domingo Faustino Sarmiento (Jaksic, 20or; Velleman, 2004), donde las encontramos justamente relacionadas con el nacionalismo intelectual hispa-

\footnotetext{
3 J. Klor de Alva (I995) considera problemática la adopción de este marco teórico para el caso latinoamericano, en el que no ve las condiciones de colonización y descolonización que se dieron en África y Asia.

4 Agradezco a Adolfo de Nordenflycht, de la Universidad Católica de Valparaíso, sus orientaciones al respecto, en comunicación personal.
}

noamericano del siglo xix. También hemos de destacar el trabajo de la ya desaparecida filóloga chilena Lidia Contreras (Contreras 1993), quien documenta con exhaustividad este periodo de 17 conflicto ortográfico, aportando observaciones que dan consistencia a la polémica y la dejan sorprendentemente abierta.

No hemos encontrado en la traductología española, de suyo poco preocupada por temas americanos, atisbos que sugieran la posibilidad de conflicto de las sociedades emancipadas con la lengua de la metrópolis en el contexto de la traducción. La traductología de línea postcolonial no parece tampoco haber advertido ninguna vinculación entre ortografía y resistencias a la imposición del castellano, y creemos que no se ha propuesto hasta ahora que la traducción haya podido figurar como estrategia de introducción de estas resistencias ortográficas.

Hecho este somero repaso de los estudios sobre la cuestión, trataremos de explicar la singular actitud de subversión ante la lengua castellana que, si bien se encuentra más o menos difusa en otros países americanos, con ecos aprobatorios incluso en España ${ }^{5}$, fue en el Chile decimonónico donde cundió de forma particularmente intensa y duradera. En esta actitud de rebelión se entretejen la ortografía, como representación gráfica de la lengua, y la traducción - gesto de afirmación soberana de las lenguas-, como forma de difundir esta representación.

Si bien, por su limitado alcance geográfico, podría considerarse que el episodio que nos interesa tendrá en la historia de la traducción un modesto lugar, nos parece significativo por diversas razones, principalmente porque demuestra, esta vez en la complicidad entre Jiménez.
5 Recordemos a Miguel de Unamuno y Juan Ramón 
traducción y ortografía, la presencia de la traducción en el enmarañado de representaciones que constituyen lo que llamamos identidad. Por 18 otra parte, tanto su duración como la intervención de la autoridad política en su abrupto final nos parecen también aspectos significativos y merecedores de atención ${ }^{6}$.

Es indudable además que la lejanía respecto a España de esta colonia situada en los confines de la hispanidad le confirió rasgos de autonomía y una cierta soltura de conducta ${ }^{7}$. Lejos del control central, este fenómeno pudo alcanzar un cierto desarrollo y difusión, ofreciéndonos la posibilidad de imaginar lo que hubiera podido ser de haber logrado medrar en las demás colonias.

Demos antes un breve rodeo por una experiencia posiblemente más familiar para nuestro ámbito: movido por su ferviente patriotismo y por la necesidad de dotar de libros de gramática a las escuelas de la nueva nación, el abogado hecho maestro Noah Webster (I758I843) publica entre 1783 y I785 tres libritos para la enseñanza elemental del inglés: un libro de ortografía (spelling), uno de gramática y otro de lecturas, los primeros libros escolares hechos en Estados Unidos. A partir de entonces, y gracias al éxito del manualito de ortografía, que se reeditó innumerables veces como The American Spelling Book, Webster pudo proseguir sus estu-

\footnotetext{
${ }^{6}$ Nos parece que el episodio que aquí analizamos podría aportar además alguna clave para la observación y explicación de los fenómenos de ortografías alternativas que se están dando a raíz de las formas nuevas de comunicación digital.

7 La libertad editorial (cuando no franca piratería) que ya explicamos en un estudio anterior (Payàs 2007), puede explicarse como producto de esta lejanía. Asimismo, no podemos dejar de señalar que la historiografía colonial chilena ha observado también la dificultad en hacer respetar en estas latitudes las leyes y ordenanzas de la monarquía así como la preceptiva religiosa (véase Sagredo y Gazmuri, 2005).
}

dios y publicaciones, entre las cuales el célebre An American Dictionary of the English Language (I828), precursor de los diccionarios que hoy conocemos con el nombre de Merriam-Webster.

La obra de Noah Webster toda ella es una argumentación a favor de la soberanía del inglés de América, de su carácter distintivo y singular, como lengua que merece ser estudiada por mérito propio, independientemente de sus orígenes europeos. Se trata de una emancipación lingüística que corre pareja a la emancipación política: así como se distinguen por su liberalismo sus constituciones civil y eclesiástica, algún día, dice Webster, el país se distinguirá por sus proezas literarias, y para ello, es preciso separarse en todo de Europa, «grown old in folly, corruption and tyranny» (Baugh y Cable, I993: 36 I) $)^{8}$.

En I789, Webster publica en Boston su ensayo sobre la reforma ortográfica. Para él, no cabe duda de que lengua y nación van de la mano: «Let us then seize the present moment and establish a national language, as well as a national government»(Webster, I789) ${ }^{9}$. La lengua americana que hay que crear será fácil de aprender, estará desvinculada de las raíces clásicas y francesas, y favorecerá una sola pronunciación. Para ello, habrá que romper con la metrópolis: «Great Britain, whose children we are, should no longer be our standard; for the taste of her writers is already corrupted, and her language on the decline. But if it were not so, she is as too great a distance to be our model, and to instruct

8 [envejece en medio de la locura, la corrupción y la tiranía. Trad. nuestra].

9 [Aprovechemos el momento presente y establezcamos una lengua nacional, así como un gobierno nacional. Trad. nuestra] 
us in the principles of our own tongue» (Baugh y Cable r993: 36r I ${ }^{\text {ro }}$.

Noah Webster estaba en Londres en 1825 . En Londres estaba también, desde i8ro, el joven exiliado venezolano Andrés Bello (I78II8ro). Si bien no se ha podido determinar que hubiera contacto personal entre ellos, las concordancias son muy notables, empezando por la formación jurídica y la derivación hacia los intereses filológicos en ambos. Los principios de soberanía y emancipación están expresados en ambos, como lo estuvieron en otros de su misma generación. Y, sobre todo, en ambos campea la bandera de la lengua, el orden gramatical y la representación ortográfica de la identidad americana. De hecho, las propuestas de simplificación ortográfica del inglés son, mutatis mutandis, equivalentes a las que Bello propuso, y sus bases conceptuales, a saber, vinculación de la escritura con la fonética y eliminación del principio etimológico como base de la ortografía, son también las mismas. Convergen y se condensan en la noción de que al Nuevo Mundo le corresponde una nueva lengua, acorde a sus hablantes y libre de las ataduras con un pasado lejano y ajeno ${ }^{\text {II }}$.

Desde Londres, en la revista Biblioteca Americana, Miscelánea de Literatura, Artes y Ciencias (1823), de la que es cofundador, y que se nutrirá mayormente de sus trabajos, Andrés Bello publica, al alimón con el colombiano Juan García del Río, unas «Indicaciones sobre

Io [la Gran Bretaña, cuyos hijos somos, no debería ya ser nuestro modelo; el gusto de sus escritores es ya corrupto, y su lengua está en decadencia. Y aunque no fuera así, está a una distancia demasiado grande para servirnos de modelo, y para instruirnos en los principios de nuestra propia lengua. Trad. nuestra]

II Hay formulaciones en sus textos que son tan parecidas que hacen pensar, si no en una comunicación personal, al menos en una lectura, de parte de Bello, del trabajo de Webster. la conveniencia de simplificar i uniformar la ortografía en América». Basándose en la autoridad de Nebrija, y con la intención de facilitar a la población americana el aprendizaje del castellano, propone disociar la ortografía de la etimología y, gradualmente, por etapas prescritas, ir acomodando la ortografía a la fonética. En lo esencial, se trataba de utilizar para cada sonido un grafema, eliminando los grafemas que no suenan: $h$ (aora) y $u$ después de $g$ y $q$ (qinto, giso), representar el fonema $/ \mathrm{x} /$ siempre por $j$ (jente), reducir a un solo fonema los que, teniendo el mismo sonido, son distintos: $s, c / c$, $q, k / c, z$ (zebo, zinco, qasa, quna) e imponer el uso de la doble $r$ para ese fonema a comienzo de palabra (rrazón). Además, desde luego, propuso eliminar la $y$ griega (mui, soi), y naturalizar otras formas ortográficas derivadas del latín o del griego, por ejemplo, sustituir la $x$ por $s$ o por cs (espresar, ecsámen).

Esta propuesta no dejó indiferentes a los demás intelectuales americanos, que se enzarzaron en largos debates en la prensa, e inmediatamente los adeptos se encargaron de adoptar las reformas, aunque no de forma homogénea ni concertada.

Ya en Chile, Andrés Bello publica en I835 sus Principios de ortolojía i métrica, donde insiste en el plan de reformas. Siendo rector de la recién creada Universidad de Chile, las reformas serán adoptadas oficialmente, gracias al impulso de otro exiliado, miembro de la Facultad de Filosofía y Humanidades de la misma universidad: el argentino Domingo Faustino Sarmiento (I8II-I888). En el prólogo de su «Memoria sobre la reforma ortográfica», que presentó a la institución en octubre de I843, Sarmiento expone las razones de la propuesta:

... como hoi no hai uso comun i constante, porque coexisten diversas maneras de 
escribir, y necesitamos adoptar una ortografía cualquiera, he creído que para librarnos de un golpe de los errores que á cada paso cometemos en la eleccion de las letras; para escusarse la mayoria de los americanos de aprender latin, ó andar años enteros atisbando la manera como están escritas en los libros las palabras, debemos consultar el modo constante que hai en America de pronunciarlas, realizando de una vez la acertada indicacion de Nebrija: 'que cada letra tenga su distinto sonido; que cada sonido tenga su distinta letra' (Contreras, I993: 33).

Así fue como, pese a las voces disidentes y al escarnio de algunos, queda instaurada en I844 oficialmente la reforma ortográfica en Chile. Y de ahí en adelante, en vista de que la Facultad tenía como una de sus atribuciones la dirección de la educación primaria del país y que, por lo tanto, se encargaba de elaborar y aprobar los libros de texto, muchos de ellos traducidos, se propaga por todo el sistema educativo nacional la nueva ortografía.

En esa ortografía, que se popularizó con el nombre de «casera», se publica la primera edición de la gramática de Andrés Bello. Y en esa ortografía Chile traducirá gran parte de los libros necesarios para las escuelas, colegios y la universidad. Al considerar que los modelos para la nueva nación independiente no pueden venir de España, que, desde su sumisión a Napoleón (I808-I8I4), ha perdido terreno irremisiblemente en cuanto a creación intelectual, Chile los buscará en otras naciones, las más modernas, las que producen ideas nuevas. De ahí que el periodo I840 -r89o, aproximadamente, esté marcado por esta militancia educativa, ejercida por los gobiernos y las élites intelectuales, que encargan y publican traducciones, a razón de tres o cuatro por año ${ }^{\mathrm{I2}}$, para complementar los esfuerzos de alfabetización y formación de la ciudadanía.

Sarmiento traduce por lo menos cuatro obras de carácter didáctico ${ }^{\mathrm{I} 3}$, proclama en varias ocasiones la necesidad de traducción ${ }^{\mathrm{I} 4}$ y defiende la legitimidad de las prácticas de apropiación que corresponden a este contexto de carencias de producción intelectual. En el prólogo a una de sus traducciones, leemos esta solemne declaración:

Los libros, que son los almacenes del saber, no vienen preparados para nosotros i tales como los necesitamos, es decir, en nuestro idioma, i para la lectura común. Los libros necesitamos hacerlos en casa, i ya que nuestro saber no alcance a crear los conocimientos de que son conductores i propagadores, podemos, vaciando, por decirlo así, en nuestro idioma, los tesones que en este genero poseen otras naciones, hacer nuestro el trabajo de todo el mundo (Figuier, I854: IV, el subrayado es nuestro).

La urgencia era grande. La imprenta no había llegado a estos confines de América sino en la segunda década del s. xix, y había que

I2 Para un análisis más detallado de la producción de traducciones, véase nuestro estudio «La Biblioteca Chilena de Traductores, o el sentido de una colección», estudio introductorio de la $2^{\mathrm{a}}$ edición de la Biblioteca Chilena de Traductores (I820-I925), de José Toribio Medina, DIBAMCentro de investigaciones Diego Barros Arana, Santiago, 2007 .

I3 De autores desconocidos: La conciencia de un niño, y La vida de Jesucristo, con una sucinta descripción de la Palestina. de Louis Figuier, Esposición e historia de los descubrimientos modernos, de Lévi Alvarès, El por qué, o la física al alcance de todos, y Manual de historia de los pueblos antiguos y moderno.

I4 La traducción, tanto en sentido estricto como metafórico, ocupa un lugar importante en el pensamiento y la obra de D.F. Sarmiento. Rebasa el ámbito de este trabajo dedicarle la merecida atención, pero no podemos dejar de recordar que Sarmiento llegó a declarar que el castellano estaba muerto (sic), y que las colonias no se emanciparían «sino abandonándolo, o traduciendo entero otro» (Velleman 2004, p. 38). 
dotar rápidamente de libros a las escuelas. La relativa bonanza política chilena había atraído a intelectuales que huían de las dictaduras de países vecinos, sobre todo a los argentinos de la que se conoció como Generación de I837, varios de ellos traductores, y Chile supo aprovecharlos en este esfuerzo de construcción de la base educativa nacional. Sarmiento, paladín de la traducción como herramienta de educación, se defendía en los periódicos de los hispanistas contrarios a la reforma ortográfica:

¿Sabe usted que los que nos dedicamos a la enseñanza, y queremos subministrar alguna idea que esté de acuerdo con lo que se sabe y enseña en Europa, sobre lejislacion, derecho, cosmografía, jeolojia, [...] ... y aun gramática, tenemos que andar a la caza de libros, traduciendo, haciendo estractos [...] porque no hai nada en castellano, o mui poco... (Contreras, I993: 44-45).

Siendo escasa la producción intelectual española, como decía otro intelectual argentino refugiado en Chile, también traductor, Juan María Gutiérrez, no quedaba sino traducir lo que otras naciones producían:

Nula, pues, la ciencia y la literatura española, debemos nosotros divorciarnos completamente con ellas, emanciparnos a este respecto de las tradiciones peninsulares, como supimos hacerlo en política, cuando nos proclamamos libres. Quedamos aún ligados por el vínculo fuerte y estrecho del idioma; pero éste debe aflojarse de día en día, a medida que vayamos entrando en el movimiento intelectual de los pueblos adelantados de la Europa. Para esto es necesario que nos familiaricemos con los idiomas extranjeros, y hagamos constante estudio de aclimatar al nuestro cuanto en aquéllos se produzca de bueno, interesante y bello (Catelli y Gargatagli, 1998: 365).

Y siendo así, ¿por qué no aprovechar la traducción para inocular las novedades orto- gráficas en el castellano de Hispanoamérica? Sarmiento instaba, por medio de la prensa, a los escritores

a vencer sus escrúpulos y formular decididamente una ortografía exacta, buena y fácil para leer y escribir con ella, sin andar consultando a la Academia, que nadie consulta, porque está muda, porque está tocada de marasmo, de inanicion incurable, $\mathrm{y}$ porque para traducir al castellano, mejor es traducir con una ortografía racional, que con esa madeja sin cuenda, ese caos de la ortografía actual (Contreras, I993: 45, cursivas en el original).

Mordaz, escribía desde Madrid mismo a los que en España argumentaban que la desviación ortográfica establecería una división entre la madre patria y sus colonias:

Éste no es un grave inconveniente ... como allá [en América] no leemos libros españoles; como Uds no tienen autores, ni escritores, ni sabios, ni economistas, ni políticos, ni historiadores, ni cosa que lo valga; como Uds aquí y nosotros allá traducimos, nos es absolutamente indiferente que Uds escriban de un modo lo traducido y nosotros de otro (citado en Catelli y Gargatagli, 1998: 370).

Para difundir esta ortografía desde el aprendizaje de la lectura, Sarmiento había publicado su Método de lectura gradual, en el que se explicaban las reformas de la ortografía y se proporcionaban las primeras lecturas: «un acendado tenía un servidor fiel, laborioso, qe abia trabajado....» (Sarmiento, 1849b: 63).

Congruente con esta preceptiva, así traducía Sarmiento la obrita de religión destinada a las escuelas del país, Vida de Jesucristo, con una descripción sucinta de la Palestina, de original desconocido, y que fue objeto de numerosas reediciones en el periodo de referencia:

El nombre de Palestina le viene de los filis- 
teos qe ocupaban una parte de él. También fué llamado Pais de Canaan, del nombre de Canaan, ijo de Cam; Judea, por la mas considerable de las tribus de Isrrael, de donde a venido el nombre de judios qe damos a sus abitantes; Tierra Prometida porqe Dios abia prometido a los patriarcas darla a su posteridad; i Tierra Santa porque Jesucristo, el fundador de nuestra relijion, vivió en ella e izo allí sus milagros. Oi día casi no conserva nombre particular... (Anónimo, I844: 3-4, cursivas del original $)^{15}$.

Y también así tradujo otra obra de la que se hicieron más de 50 ediciones, La conciencia de un niño, también de autor desconocido:

Soy mui feliz: tengo excelentes padres que se ocupan de mí. Su bondad provee a todo lo que me es necesario. Sí: son mui buenos padres, mui dignos de mi amor! (Anónimo, I849: 3$)^{16}$.

Como ya hemos tenido ocasión de explicar (Payàs 2007), en ningún otro país tuvieron tanto eco las ideas ortográficas. Aunque también llegaron a otros, y tenían adeptos incluso en España, sólo cuajaron y proliferaron en Chile. Decía el gramático chileno Enrique Nercasseau, uno de los discrepantes, que era «vicio peculiar hoi dia, por desgracia nuestra, solo de Chile i de alguna que otra provincia de la República Arjentina» (Contreras, I993: 145). Resulta ilustrativo el hecho de que en I874, cuando Rufino Cuervo quiso reproducir en Colombia la gramática de Andrés Bello complementada con notas suyas, como sólo corrían impresiones hechas en Chile, país de origen de la edición, tuvo que pedir a los editores que la

I5 Enrique Nercasseau, en un discurso de 1884 en contra de las ideas de Sarmiento y a favor de la ortografía académica, observa que los libros impresos desde 1843 hasta I846 en Chile «llevaban el sello de esta escritura sin haches i sin ues mudas» (Contreras, op. cit., p. I79).

I6 En la edición que consultamos no se corrige la $q$. pusieran en ortografía académica, ya que había sido impresa «en la ortografía casera usada en el país en que la sacó a luz» (Cuervo, I954: 9II) ${ }^{\mathrm{I7}}$.

Sin embargo, como ya señalamos, no hubo autoridad que pudiera imponer una ortografía reformada uniforme, y la realidad fue que coexistieron durante ese periodo diversas formas, sin que las imprentas o casas editoras de libros y periódicos convinieran en una única ortografía y a veces incluso sin una misma ortografía en la misma imprenta ${ }^{18}$. Las reformas más aceptables y que más se difundieron fueron las que había propuesto Bello: el reemplazo de la $g$ por la $j$ cuando corresponde a este sonido (jeografía), y el de la $y$ por $i$ cuando tiene función vocálica (mui). No siempre se aceptó la eliminación de las letras mudas, ni hubo coincidencia en cuanto a lo que debía hacerse con las letras $c$ y $z^{19}$.

Hacia fines de siglo se produce un rebrote de carácter muy radical en las ideas ortográficas. La existencia de un cierto movimiento neográfico de ramificaciones internacionales ${ }^{20}$ dio un nuevo aliento a las ideas ortográficas en Chile. Si bien sus adalides locales explicaron el renovado interés como continuidad del trabajo

${ }^{17}$ Es de interés señalar que en Colombia también hubo algunos períodos de indefinición ortográfica, como Cuervo lo da a entender en la siguiente aclaración, que es continuación de la cita: «Los editores tuvieron la benevolencia de acceder a mis deseos, a pesar de no ser ésta la que siguen en las obras que imprimen por su cuenta».

I8 Observa Sarmiento en su reseña de los periódicos que estaban a favor y en contra de la reforma (I849: 503509) que la ortografía de un periódico o imprenta variaba según el impresor que estuviera trabajando en ella en ese momento.

I9 En los escritos del propio Sarmiento encontramos distintas ortografías, e incluso dentro de un mismo libro, como puede verse, por ejemplo, en De la educación popular, Imprenta de Julio Belin y Compañía, Santiago, I849.

${ }_{2 \circ}$ Como lo atestigua la publicación de una «tentatiba bibliografika», de la que hablaremos más adelante. 
de Bello y Sarmiento, que, según decían, por desidia de sus sucesores había sido abandonado por la Universidad (Contreras, I993: 260-6I), y aunque estos autores se encuentren citados sistemáticamente en los manifiestos que los neógrafos publicaron (transcritos incluso en «ortografía rrazional», como si hubieran sido parte de este movimiento), los materiales que he tenido la oportunidad de analizar hasta ahora no parecen avalar ninguna relación ideológica de fondo con el movimiento anterior. Este replanteamiento ortográfico no se propuso como una forma de facilitar a la ciudadanía el aprendizaje y uso de la lengua castellana, sino que parece más bien situable en el contexto de las experimentaciones con las lenguas de las que fueron parte la creación de lenguas artificiales como el esperanto y el volapük, así como la mucho menos conocida "lengua católica» del chileno Alberto Liptay, todas ellas creadas entre los años I880 y I89o. A diferencia de Andrés Bello y Domingo Faustino Sarmiento, los neógrafos no vinculan la ortografía a una normalización por vía de la educación, sino que parecen ligados, por una parte, al libertarismo de Herbert Spencer y Stuart Mill y, por la otra, a una red de iniciativas más bien marginales que estaban surgiendo en diversas partes del mundo en favor de reformas ortográficas. Una especie de «internacional» neográfica, de espíritu transgresor, anarquizante, defendida en Chile por un puñado de radicales que, como el Fiel Ejequtor que dimos a conocer al comienzo, reivindican el derecho a escribir a su modo. Véase si no la respuesta que da precisamente el Fiel Ejequtor a quienes piden que intervenga la autoridad para imponer el orden ortográfico: a la autoridad no le compete el asunto, dice,

$\boldsymbol{I}^{\circ}$ Por aberlo qosteado yo i ser aqto ofizioso de mi parte.
2. ${ }^{\circ}$ Porqe la autoridad no tiene nada qe azer qon los abisos partiqulares.

$3{ }^{\circ} \quad$ Por ignorar qe en Chile se pudiese qastigar al indibiduo qe perteneze a una seqta ortográfiqa.

$70^{\circ}$ Porqe biendo qe los diarios i asta las leyes en Chile están en jerga, qrei qe no abria inqonbeniente en inbentar una para mi uso» (Contreras, I993: 2I9).

De hecho, los neógrafos pasarán del uso de la $q$ al de la $k$, y así publicarán varios opúsculos y libros, empezando por La ortografia rrazional, del mismo (ahora) Kabezón, que empieza así:

El mayor grado de perfekzion de ke la eskritura es suszeptible, i el punto a ke por konsigiente deben konspirar todas las rreformas, se zifra en una kabal korrespondenzia entre los sonidos elementales de la lengua, i los signos o letras ke an de rrepresentarlos, por manera ke a kada sonido elemental korresponda imbariablemente una letra, i a kada letra korresponda kon la misma imbariabilidad un sonido (Kabezón, 1902: 7).

En «ortografía rrazional» se publicarán, en Quillota (Killota), Valparaíso (Balparaíso) y Santiago, una veintena de obras (originales) en el espacio de unos veinte años, las más de ciencias aplicadas: Kálkulos sobre las kañerías de agua (1895) El kambio de komposicion ke experimenta el agua de «El Salto» durante el imbierno (1896) Las funziones iperbólikas i su aplikazión a los problemas de injeriería eléktrika (I9I3) Proye$k$ to de Lei sobre medidas nazionales (I9I4), y La unifikazion de las medidas (1897) en la que se equipara la Babel de las lenguas a la confusión entre los distintos sistemas de pesos y medidas, y se recuerdan las iniciativas «kosmoglósikas» que surgieron en esos años. Nos parece sinto- 


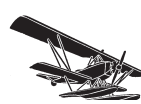

24

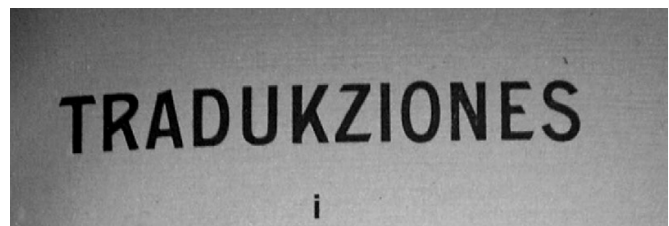

\section{TRADUKTORES.}

NOTAS I DIGRESIONES LEIDAS

POR

MANFREDO BLUMER

EN LA SESION ZELEBRADA POR LA AKADEMIA

DE LOS SAGRADOS KORAZONES DE BALPARAÍSO, EL 30 DE SETIEMBRE DE 1911.

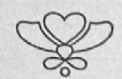

KILLOTA, FRANZISKO ENRRIKEZ, KALLE DE SERRANO, 29 , 1912. mática, en este corpus, la publicación, en I896, de una bibliografía de materia neográfica de varios países de Europa y América: Neógrafos kontemporáneos: Tentatiba bibliográfika, como indicativa del grado de conciencia que estos autores tenían de pertenecer a un movimiento supranacional. Otro texto curioso es un opúsculo titulado Tradukziones y Traduktores (I9I2), de Manfredo Blumer, una arenga contra las malas traducciones peninsulares, las libertades que se toman los traductores y editores, la falta de diccionarios, la degeneración de la lengua española y el esnobismo de los académicos y críticos. Exculpa en parte a los pobres traductores porque «bibir en pleno pekado gramatikal no es achake solo de intonsos i modestos traduktores

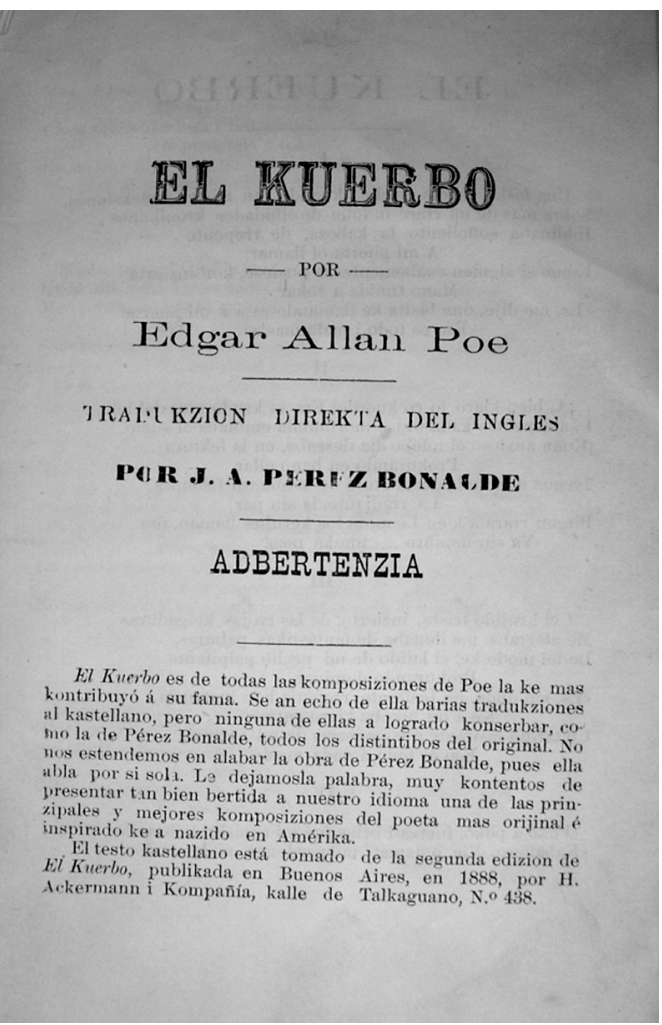

kastellanos sino tambien de los mas pingorotudos miembros de la Académie Française [...]»y todo lo que se les critica «lo azen en la onrrosa kompañía de klásikos i akadémikos» (Blumer, I9I2: 22).

En cuanto a traducciones, según consta en la Biblioteca Chilena de Traductores, de José Toribio Medina, se publicaron tres obras: una versión neográfica de la traducción hecha por el poeta venezolano Pérez Bonalde del poema The Raven (El Kuerbo), de Edgar Allan Poe; una novela italiana de folletín, de Adolfo Maspes: L'amante (La Kerida), traducida por Kárlos Gonzalez Ugalde en I897, y de Georges Denigès, Exposé elementaire des principes de la théorie atomique (Esposizión elemental de los prinzipios 


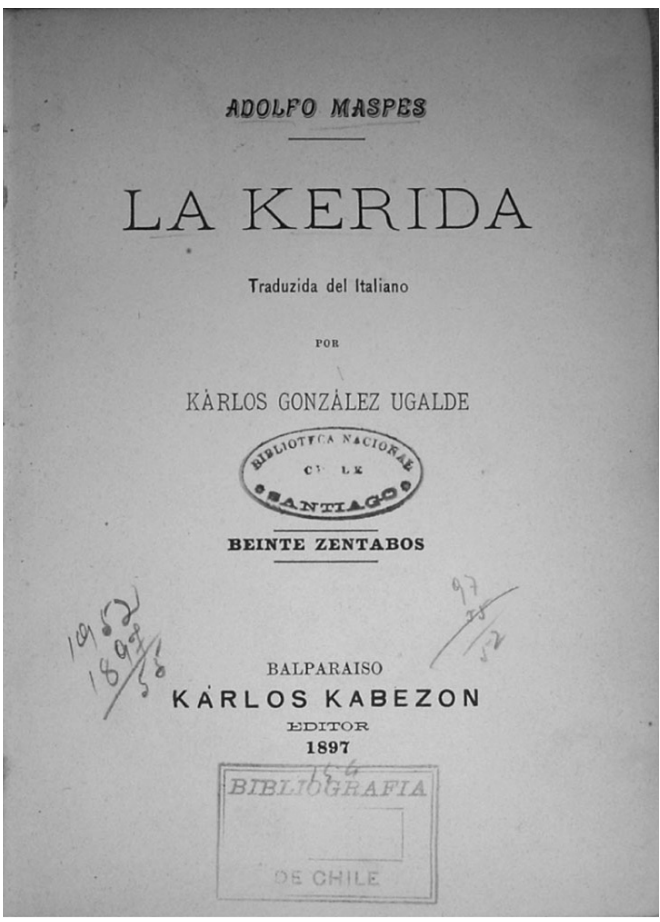

fundamentales de la teoría atómiqa), traducido por Manuel A. Délano, Sozio Onorario del Qolejio de Farmazeutiqos de Madrid, miembro de la Soziedad Zientífiqa de Chile (sic) etc..., en I893. Medina no parece haber advertido una cuarta traducción, de 1904, también de Kárlos González Ugalde: Kontra la Korriente. Pensamientos azerka de la abolizion de la pena de muerte propuesta en el nuebo kódigo penal italiano, traducción parcial, según parece, de una obra de Rafelle Garofalo.

\section{CONCLUSIÓN}

La línea que va del castellano inicial en América al castellano de hoy no es, pues, tan directa

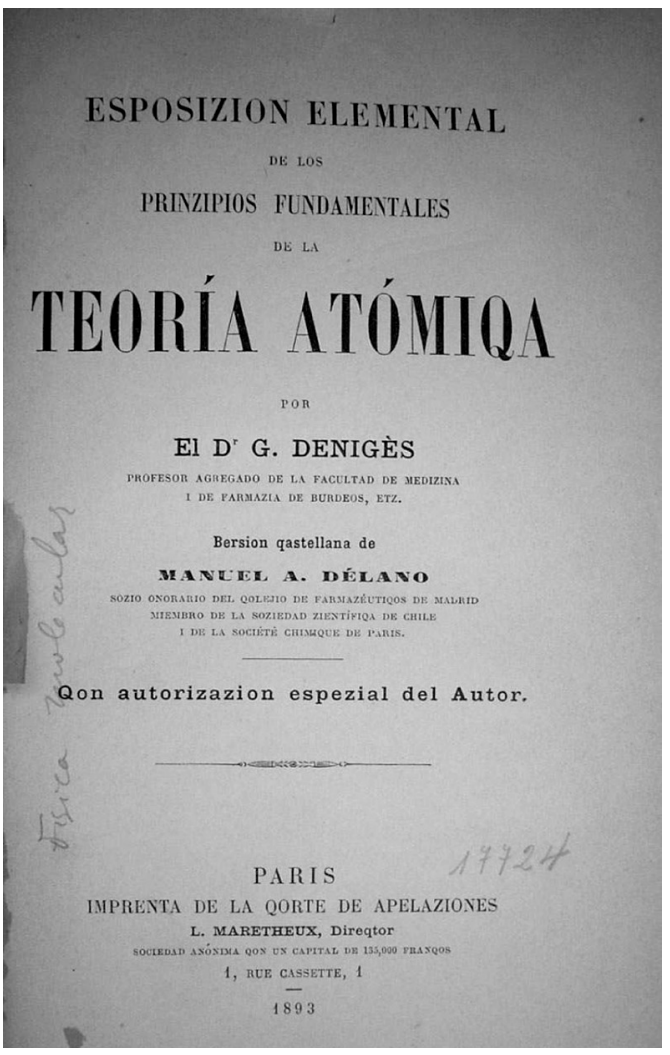

como se puede suponer. Se suele considerar que, una vez raleado el territorio lingüístico americano, desaparecida buena parte de las lenguas autóctonas, y transformadas las restantes por obra y gracia de su alfabetización y gramaticalización, el castellano se impuso naturalmente como la lengua del mestizaje y de las nuevas naciones. Es probable que esta adopción haya sido sólo aparentemente dócil, ya que no podía dejar de percibirse como paradójico para el nacionalismo e hispanoamericanismo decimonónicos que la lengua que sirvió para conquistar y colonizar fuese ahora la que hubiera de servir para construir las nuevas naciones. Las rupturas con los modelos literarios o estéticos peninsulares ilustran algunas de las formas de 


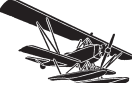

26

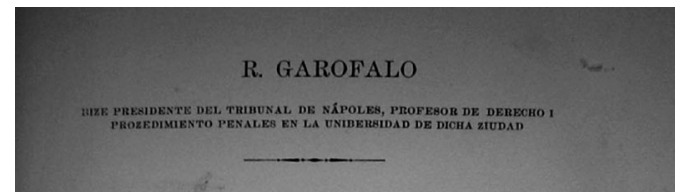

KONTRA LA KORRIENTE

\section{PENSAMIENTOS}

AZERKA DE LA ABOLIZION DE LA PENA DE MUERTE PROPUESTA EN EL NUEBO KÓDIGO PENAL ITALIANO

TRADUKZION KASTELLANA

DE

KÁRLOS GONZÁLEZ UGALDE

PREZIO: 10 ZENTABOS (15 ZENTIGRAMOS DE ORO)

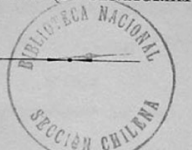

KILLOTA

KÁRLOS KABEZON

1904

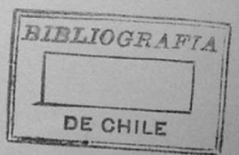

hacer frente a esta incómoda contradicción. No obstante, fuera de estas manifestaciones literarias, de proyección limitada, nada podía hacerse contra una lengua que ya era mayoritaria y en la que era urgente alfabetizar y dar lecturas a las escuelas. Esta lengua castellana, con su carga de excepciones e irregularidades, resabios del latín y griego, parecía a los pedagogos poco dúctil, difícil de enseñar, y la propuesta de la reforma ortográfica podía considerarse como una transacción aceptable. Ése es el espíritu que anima a Noah Webster y a Andrés Bello. Webster lo materializará en sus cartillas y, sobre todo en su diccionario; Bello, además de la gramática, propondrá una reforma ortográfica general, que no cuajará en todos los países pero que retumbará en el lejano Chile, frontera de la hispanidad, durante más de cien años, primero con gran fuerza, por voz y obra de Domingo Faustino Sarmiento, y luego, intermitentemente, impulsada por vientos de distintas procedencias, hasta el último estruendo de los neógrafos, que concitó las voluntades que reclamaban orden y autoridad. La Hispanoamérica imaginada (Anderson, I99i) por los próceres de las independencias, con una lengua que "sonaría» como castellano pero que se representaría de otra manera, se disuelve así, definitivamente, por decreto gubernamental, en 1927: «Adóptase como ortografía ofical, la de la Real Academia Española para todos los documentos de la administración pública de Chile. Este empezará a rejir, para todos los servicios públicos, el I2 de Octubre próximo, en homenaje al Día de la Raza» (Contreras, 1993: 362).

La traducción se entreteje en esta historia singular. En el primer episodio su presencia es fundamental: ejercida desde la propia autoridad educativa del país, e impulsada por sus élites intelectuales, servirá para adueñarse de la producción foránea que necesita Chile y, además, será la vía para poder inocular la reforma ortográfica propuesta por Andrés Bello. La máquina de la reforma seguirá andando, unas veces sumando y, otras, restando fuerzas. En el episodio final, la iniciativa del grupo de los neógrafos, que representan una vanguardia no literaria, de carácter a veces anarquizante y lúdico, desenfadada y no del todo insatisfecha de su marginalidad, se sitúa en un plano distinto. Si bien se sigue invocando a Bello y a Sarmiento como autoridades, parece tratarse más bien de una estrategia de legitimación. Cabe dudar de que a los neógrafos les haya movido una ideo- 


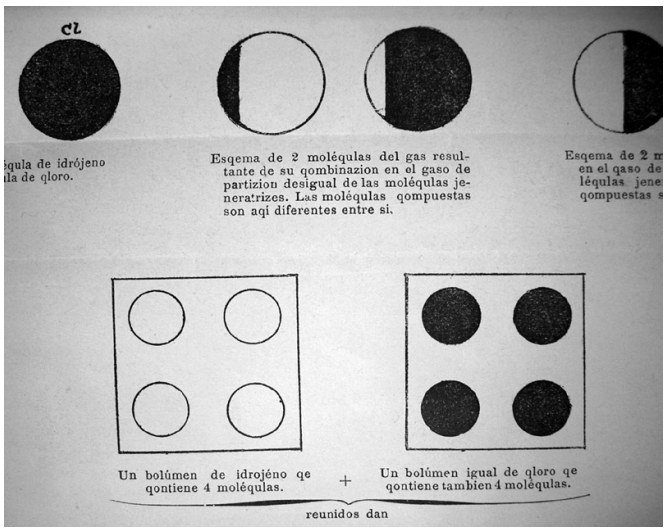

logía hispanoamericanista, ni siquiera la unión ortográfica del país. Les motiva más bien un deseo de modernidad, de pertenecer a una red internacional de mentes liberales, disidentes: una «seqta ortográfiqa», como dice el Ejequtor. Por eso resulta difícil situar ideológicamente las escasas traducciones que este movimiento generó.

Sin embargo, nos parece posible sugerir estos breves trazos críticos, que cabría someter a verificación con nuevos ejemplos: el gesto de trasladar a «ortografia rrazional» el poema de Poe, traducido por el ya entonces reconocido poeta y académico venezolano Juan Antonio Pérez Bonalde $^{2 \mathrm{I}}$, parece demostrar que la traducción es capaz de doblegar la lengua literaria para que ceda a la presión de la reforma. Por su parte -y esta interpretación nos parece más reveladora aún de las funciones transformadoras de la traducción-, por el efecto de verosimilitud del lenguaje científico y de la propia traducción científica, la traducción de la obra de Denigès sobre las teorías atómicas (contemporánea de varias publicaciones científicas originales,

\footnotetext{
${ }^{21}$ que, dicho sea de paso, habiendo muerto años antes, no pudo ejercer oposición.
}

incluso actas de congresos, escritas también en neografía) bosqueja el inquietante horizonte de una normalidad ortográfica distinta, la misma que pretendía el manual sobre «unifikazion» de pesas y medidas que publicaba Kabezón en Killota: la normalidad propia del lenguaje universal de los fenómenos de la naturaleza.

Nota: La autora agradece en particular a la Biblioteca Nacional de Chile, en Santiago, y al Fondo Budge de la Pontificia Universidad Católica de Valparaíso, haberle permitido fotografiar las obras que aquí se reproducen.

RECIBIDO EN ENERO 2008 ACEPTADO EN FEBRERO 2008

\section{BIBLIOGRAFÍA}

Anderson, B. (I99I). Imagined Communities, Londres-Nueva York: Verso.

Baugh, A.C. y Cable, T. (1993). A History of the English Language, London: Routledge.

Bello, A. (I823). «Indicaciones sobre la conveniencia de simplificar i unificar la ortografía en América». Londres: Biblioteca Americana, o Miscelánea de Literatura, Artes y Ciencias t. I, pp. 50-62.

Bello, A. (I884) [1835]. «Principios de ortolojía i métrica», Obras Completas de Don Andrés Bello. Vol. V. Opúsculos gramaticales. Santiago: Dirección del Consejo de Instrucción Pública, pp. 3-229.

Blumer, M. (I9I2). Tradukziones i traduktores. Killota: Franzisko Enrrikez.

Catelli, N. y Gargatagli, M. ( 1998). El tabaco que fumaba Plinio, Barcelona: Ed. del Serbal.

Contreras, L. (I993). Historia de las ideas ortográficas en Chile. Santiago: Biblioteca Nacional.

Cuervo, R.J. (I954). «Notas a la gramática de la lengua castellana de D. Andrés Bello», en R. J. Cuervo, Obras, Tomo I, Bogotá: Instituto Caro y Cuervo, pp. 907-II57.

Granados, A. y Marichal, C. (comp.) (2004). Construcción de las identidades latinoamericanas. Ensayos de historia intelectual, siglos XIX y XX. México: El Colegio de México. 
Jaksic, Iván (200I). Andrés Bello o la pasión del orden. Santiago, Ed. Universitaria.

Kabezón K. (I896). Neógrafos kontemporáneos. Tentatiba bibliográfika. Santiago: Imprenta Zerbantes.

28 [Kabezón, K.] (I897). La unifikazión de las medidas, Balparaiso: Kárlos Kabezón.

Kabezón K. (1902). La Ortografía Rrazional. Killota: Kárlos Kabezón.

Klor de Alva, J. (1995). «The postcolonization of the (Latin) American experience: A reconsideration of 'Colonialism', 'Postcolonialism', and 'Mestizaje'», en Prakash, Gyan, After Colonialism, Nueva Jersey: Princeton University Press.

Medina, J.T. (2007). Biblioteca Chilena de Traductores (1820-1925), ( $2^{\mathrm{a}}$ ed. a cargo de Gertrudis Payàs, $\mathrm{y}$ la col. de Tirado, C.) Santiago: DIBAM-Centro de Investigaciones Diego Barros Arana.

Mignolo, W. (I986). «La lengua, la letra, el territorio (o la crisis de los estudios literarios coloniales)», Dispositio, XI-28/29, pp. 137-I6o.

Mignolo, W. (1997). The darker side of the Renaissance: Literacy, territoriality, colonization, Michigan: University of Michigan Press.

Newman K. (1896). El kambio de komposición ke esperimenta el agua de "El Salto» durante el imbierno. Notan embiada a la Soziedad Zientifika de Balparaiso. Santiago: Imprenta i enkuadernazión Rroma.

Payàs, G. (2007). «La Biblioteca Chilena de Traductores, o el sentido de una colección», estudio introductorio de la $2^{\text {a }}$ edición de la Biblioteca Chilena de Traductores (I820-I925), de José Toribio Medina, Santiago: DIBAM-Centro de Investigaciones Diego Barros Arana.

Sagredo, R., y Gazmuri, C. (2005). Historia de la vida privada en Chile. El Chile tradicional, de la Conquista a I840, Santiago: Taurus.

Salazar, A.E. (1898). Kálkulos sobre las kañerías de agua. Ensayo de unifikación de las formulas ususales $i$ de simplifikazión de los kálkulos basada en la nozión de zirkuito idráulico. Santiago: Hume i Ka.

Salazar, A.E. (1913). Las funziones iperbólikas i su aplikazión a los problemas de injenieria eléktrika. Killota: Franzisko Enrríkez, Finka Andonaegi.

Salazar, A.E. y Newmann, K. (I9I4). Proyekto de Lei sobre medidas nazionales. Balparaiso: Franzisko Enrrikez.

Sarmiento, D.F. (1843). «Memoria sobre ortografía americana». Anales de la universidad de Chile, vol. I, pp. I77-I98, Santiago.
Sarmiento, D.F. (1849). De la educacion popular. Santiago: Imprenta de Julio Belin y Compañía.

Sarmiento, D.F. (I849b). Método de lectura gradual. Santiago: Imprenta de Julio Belin y Compañía.

Velleman, Barry (2004). "Antiacademicismo lingüístico y Comunidad Hispánica: Sarmiento y Unamuno», en La batalla del idioma, José del Valle y Luis Gabriel-Stheeman (eds.), Frankfurt: Iberoamericana-Vervuert.

Webster, N. (I789). «An Essay on the Necessity, Advantages and Practicality of Reforming the mode of Spelling and of Rendering the Orthography of Words Correspondent to Pronounciation", en Dissertations on the English Language: With Notes, Historical and Critical, to Which is Added, by way of Appendix, an Essay on a Reformed Mode of Spelling, with Dr. Franklin's Arguments on that Subject, Boston: Isaiah Thomas and Co.

\section{TRADUCCIONES CITADAS}

Anónimo (1844). Vida de Jesucristo, con una sucinta descripción de la Palestina (trad. D.F. Sarmiento). Santiago: Imprenta del Progreso.

Anónimo (I844). La conciencia de un niño (trad. D.F. Sarmiento), Santiago: Imprenta del Progreso.

de la Kuadra Silba, A. (I906). Kuesta Arriba. Santiago: Imprenta i enkuadernasión «Chile».

Denigès, G (1893). Esposición elemental de los prinzipios fundamentales de la teoría atómiqa (trad. Manuel A. Délano), Paris: Imprenta de la Qorte de Apelaziones.

Figuier, L. (1854). Esposición é Historia de los Descubrimientos Modernos (trad. D. F. Sarmiento), Santiago: Imprenta de Julio Belin.

Garofalo, R. (I904). Kontra la Korriente. Pensamientos azerka de la abolizión de la pena de muerte propuesta en el nuebo kódigo penal italiano, (trad. Karlos González Ugalde), Killota: Kárlos Kabezón.

Lévi Alvarès, D.E. (I849). El por qué, o la física puesta al alcance de todos, (trad. D.F. Sarmiento), Santiago: Imprenta de Julio Belin i Ca.

Lévi Alvarès, D.E. (I849). Manual de la historia de los pueblos antiguos $i$ modernos, (trad. D.F. Sarmiento), Santiago: Imprenta de Julio Belin i Ca.

Maspes, A (1897). La Kerida (trad. Kárlos González Ugalde), Balparaíso: Kárlos Kabezón.

Poe, E. A. (1895). El Kuerbo (trad J. A. Pérez Bonalde), Balparaíso: Franzisko Enrrikez. 